\title{
In the Forest Between Us
}

Lucy Cash, Independent Artist

\section{Scene 1}

Let's say, both of you find yourselves in a place deep inside an unfamiliar forest. The comforting trail of breadcrumbs you left behind is already a vulnerable memory. Ahead lies difficulty and wonder in equal measure. Time moves differently here and as if summoned from nowhere you encounter an inhabitant of the forest. It could be a bear, or a crow or a deer. Perhaps it's a fox. Yes, a fox-a bright smear of red in the soft greys and greens. Startled, you stop moving and as the fox looks at you and you look back at it, its presence stirs a sense in you. Something incomprehensible-outside of what you know - something strange and exhilarating and unfathomable-beyond any language. You look at each other-three sets of eyes held in a long exchange. And then the fox is gone; the spell is broken. Neither of you have any words to describe what has just happened. Yet the encounter sustains something between you; and the shadow of the fox, accompanies you. You start walking again and without trying to name what has passed (because you can't) you recognise that this encounter is what you were looking for.

My practice is driven by a need to begin with the familiar in order to find the edges of the unfamiliar: the savage and ridiculous, wayward and preposterous that make up the place where something-however small-has not already been captured and classified and tamed. The brink that is both exhilarating and uncomfortable.

Coming from a background in collaborative performance making, I like to find this boundary through dialogue, through exchange.

Within this exchange as a necessary condition, there is an unspoken trust in your fellow dialoguer, and an acceptance of forgetting as well as remembering. This is a small but significant feat, as it is the forgetting or the remembering of, for instance, breadcrumbs that establishes or de-stabilizes what grows between you moment by moment. It's interesting that the original meaning of trust is 'strong' and that when we give and receive trust it creates a bond of strength that in the best creative relationships allows space for dependence, independence and what we might call 'interdependence'. In biology interdependence exists in many different kinds of contexts and in in varying modes between different kinds of organisms. For me, thinking about these ideas temporally as well as spatially makes the metaphor of the forest in relation to a practice that seeks the not-yet-known strongly resonant. And whilst the incomprehensible, (in the sense of the place not contained by what we know) cannot be summoned to order,

The International Journal of Screendance 5 (2015). 
a practice through dialogue might seek to track the kind of conditions that could allow its appearance. For example, in an exchange with a collaborator, the 'blindspots' in my understanding are frequently revealed, allowing me to move to a fuller assimilation of an idea. Through this fuller understanding of what is already known for myself (as well as what is known for her), it's possible to clear space for the unknown to appear.

Matthew Goulish wryly describing the beginning of what became the performance company Goat Island with whom I was an associate member 2005 - 2009, reminds me how the edge of our personal community extends temporally as well as spatially. He writes,

in 1987, we invited Tatsumi Hijikata, legendary Japanese dancer and founder of Butoh, to join our company. His death in 1986 made him available. He accepted, and he often visited our rehearsals in the form of a ghost, taking part in discussions, delicately responding to our starting point. $^{1}$

Perhaps Hijikata by his ethereal nature also reminds us of the ongoing conversation we have with the parts of ourselves that remain hidden, as well as the unspoken residues that collect between individuals within a collaborative project.

To tread carefully for a moment: my pursuit of the incomprehensible doesn't intend to privilege the subconscious imaginary or fetishize the irrational or eccentric. Instead, by dealing with different materialities and the ethics and ecologies that these produce I intend to follow wherever I can the moments in which new kinds of relationships and subjectivities come into being. Whether this is the unexpected meaning generated by the combination of sound and image within a moving image work, or the more prolonged exploration of dependence and independence that takes place when two artists attempt to generate a collaborative work together.

\section{Scene 2}

You make a seal with an individual or a series of individuals and this seal creates an involuntary contract which writes itself according to the chemistry between you.

As you work together in a studio as we have, you sense and test what the rules of this contract are. You discover what is possible and the further you test, the more you learn about what is possible.

In this way the working arrangement is much like a particular view of fate or the possibilities that life at large presents. There is a constellation of prefigurations, but there is also a set of variables, and those rely on how you manage to use what is there practically and emotionally and magically in front of you... Everything we had mentioned or focussed on, acted upon us, 
even the incidental played a part in how we activated the ideas in the room. $^{2}$

These are words the performance-maker Karen Christopher wrote in relation to a week of research we carried out in February 2015.

The way of tuning the 'prefigurations' and the 'variables' is often the difference between the-thing-we-can't-name-but-whose-appearance-we-desire and hitting our heads against the brick wall of what's already known and familiar. Can we anticipate the unexpected? Will we recognise the unrecognisable?

To surrender to this 'seal' is what's required. The seal is an act of dependence. The root of which contains movement. Dependence is 'an action growing out of another action' Dependence feels responsive, confronting, inexplicable, fragile and resilient. It feels spatial, but I wouldn't know how to draw it. Glancing outside my window, the complexity of cloud shapes drifting through a sky of blue and gold feel like they might offer a temporary illustration. If so my dependence might look like this:

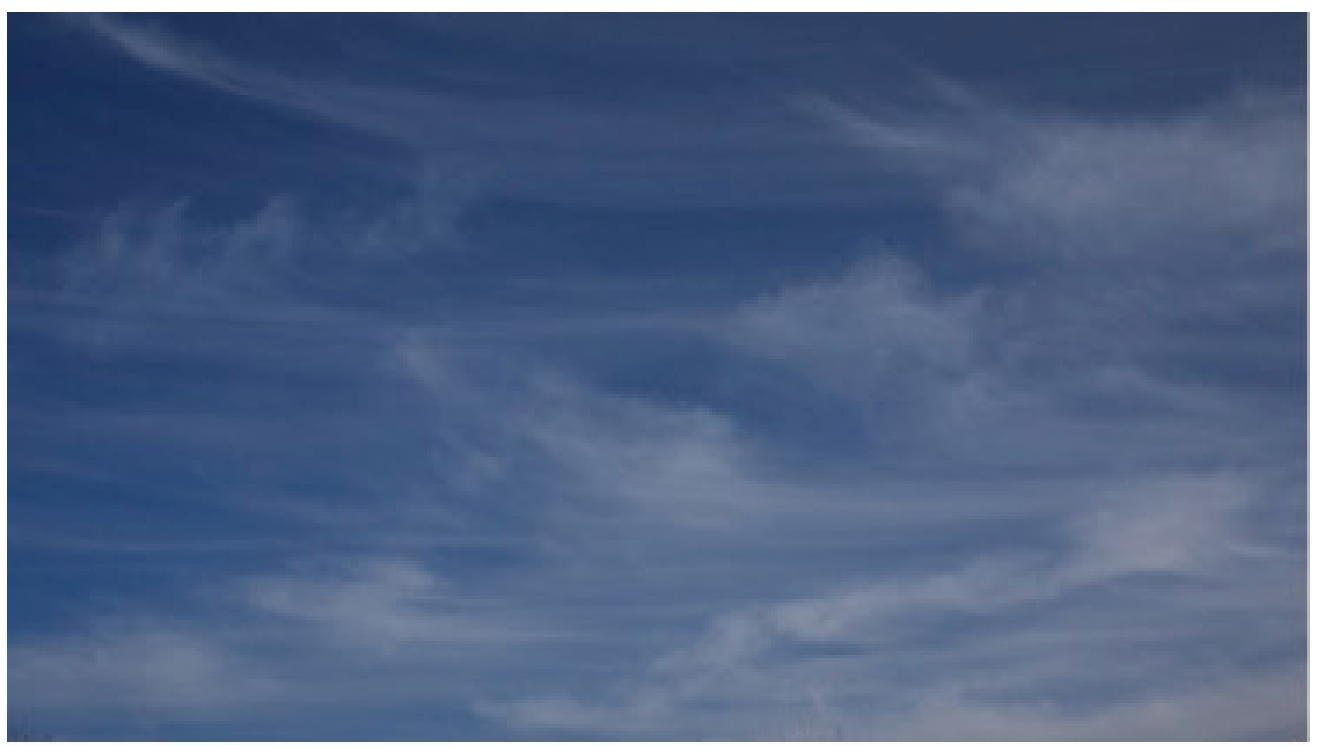

Photo: Lucy Cash

A pause. I have a Skype call with Veronica Thorseth ${ }^{3}$-a dancer in Bergen, Norwaywho in 2014 invited me to take part in a series of conversations with a group of Norwegian artists (from visual arts, theatre and dance) about site-specific work and the relationships between making work and its context and environment. She talks about how the conversations we had last year are still being referred to by the members of 
the small dance community in Bergen. We acknowledge the gratitude we both feel for the perspective offered by the other on our separate communities.

I think about all the rigorous generosity I've been lucky enough to experience in the dialogues that have sustained me over the last ten years-in particular an on-going connection with the choreographer Christina Ciupke in Berlin. In 2011, curious to articulate elements of this conversation in another form, I asked Christina whether she would be willing to experiment on an unfunded moving image work. She agrees and we call the work Conversation Piece \#1 (Palm Trees of Hackney). ${ }^{4}$

The piece explores the relationship between the process of looking, thinking and then responding to a particular idea within a specific frame. The frame is both cinematic and also conceptual-relating to the particular curiosities and concerns which form the foundation of our on-going dialogues. It explores the relationship between stillness and movement-both in the outside, everyday world, and in the movement of our thoughts. The film was made within a specific duration of time, (two days initially, and then a further week) in which we exchanged neighbourhoods, formulated and filmed a journey through our borrowed neighbourhood and then constructed a film.

Usually we are together in our different neighbourhoods and so when I go alone to Kreuzberg, I experience this part of the city differently. I observe previously unseen elements and notice new details whilst familiarising myself with a particular route around Christina's apartment block. I try to get beneath the surface of the city, whilst thinking about the frequent conversations I have with Christina about movement and pattern. Christina comes to London and does the same in my neighbourhood. We then place our individual thoughts and images next to each other, in an edit, seeing if we can trace the path of our thoughts.

We show the work in "Still Moving," an exhibition at Siobhan Davies studios and contextualise the film as an invitation to the viewer to follow their own thread of attention through our exploration of conversation in different forms. I describe the work like this:

As an artist working on unconventional collaborations with many different kinds of people, I'm often fascinated by how the most fruitful collaborations begin with a very particular kind of conversational exchange-the form of which is full of movement. The conversation meanders, takes a walk, changes rhythm ... all the while revealing delicate and particular patterns of thought. It's almost impossible to document this kind of conversation-its quality is as much in the silence and rhythm of the pauses as in the words themselves. When I take a walk in a city, I often notice how my rhythm of thinking is affected by what I see and how what I see is affected by my quality of thinking: my imagination continually shifting between remembering one thing or imagining an other (perhaps from a fragment of 
conversation I overhear) whilst all the time perceiving other things all around me.

This project blurred the edges between dependence and independence. Our independent observation of particular, partially familiar places felt fragile, resilient, obstinate, solitary, self reliant and responsible. It felt spatial, but I wouldn't know how to draw it. Glancing out of my window, the blue and gold sky offers this in the way of a diagram for independence:

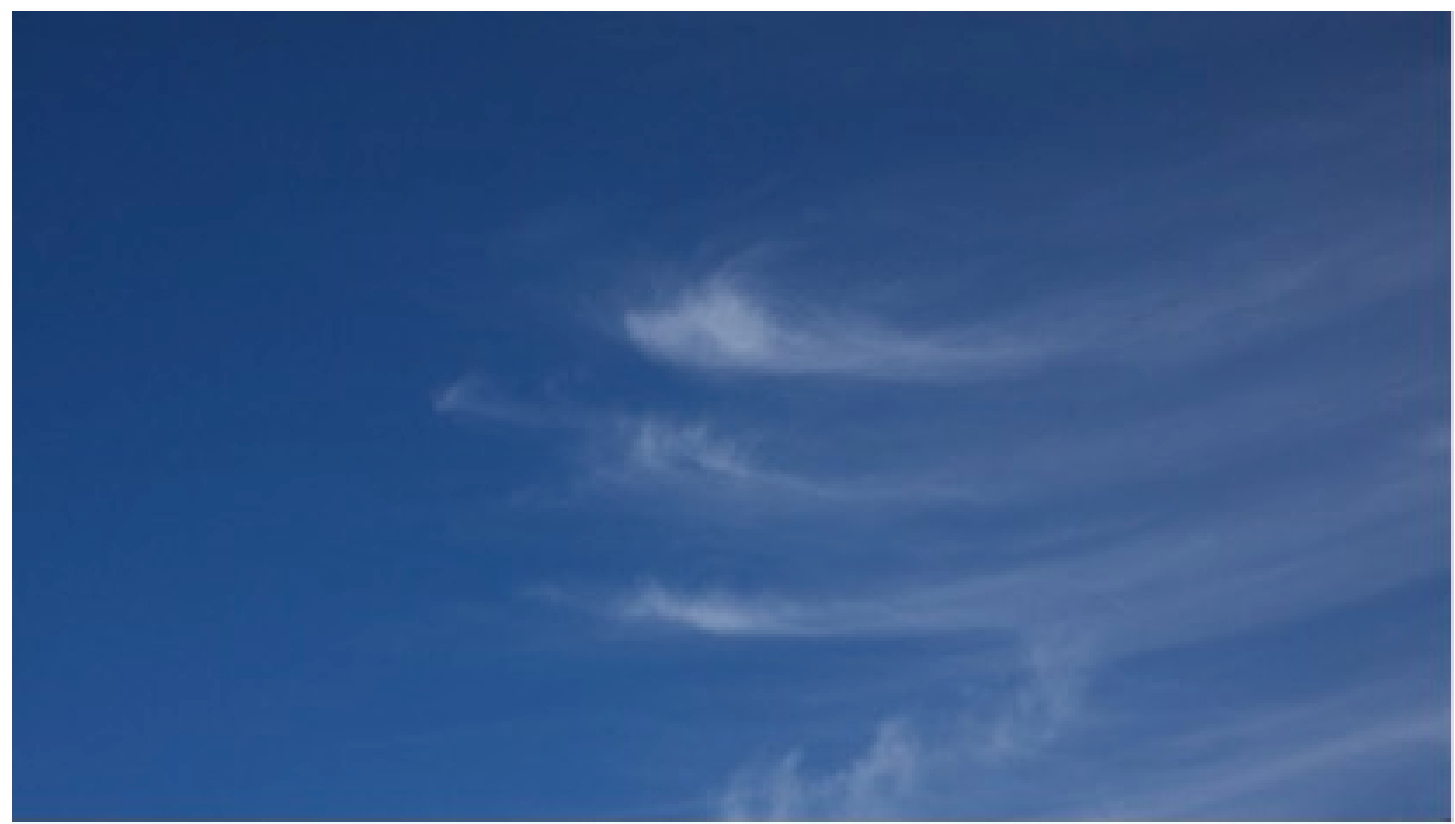

Photo: Lucy Cash

\section{Scene 3}

A large table in an apartment. A group of five women talking animatedly. Sheets of paper with scale drawings and lists in the space between them.

Back in the early 2000s when there were more Screendance festivals in the UK, or when if you were an independent artist it was still possible to get funding to visit a festival abroad, I would regularly fall into conversations with a group of extraordinary womenall making Screendance work. This group usually comprised of Becky Edmunds, Claudia Kappenberg and Chirstinn Whyte. We often sought refuge from what we perceived as a sensory overload, (MTV style screenings of up to ten or more short films in fast succession) in the bar, or outside of the venue to catch some fresh air or smoke a cigarette. We were united in our frustrations and desires for something different-for some other way of engaging with this form that is called Screendance and for a 
different balancing of attention and demand. Our conversations circled around making connections with other art forms or renaming Screendance altogether. (In the latter regard we playfully plotted a séance with Maya Deren in order to seek her advice!).

Then in 2009 I was fortunate enough to receive a fellowship from South East Dance. I knew that what I needed most at that point as an independent artist in London was to have the resources to enable a more frequent coming together of this group of women-to temporarily establish a community I was craving. So I invited Becky and Claudia and Chirstinn to form a curatorial group and to create a festival with me. Sitting somewhere between a choreographed exhibition and exhibited choreography, this curation called "What if ..." took place at Siobhan Davies Studios, through an invitation from Gill Clarke at Independent Dance. Having extended her invitation, Gill joined our curation and our exhibition / festival was folded into the line of 'What' festivals that she originally initiated. ${ }^{5}$

This dialogue enabled us to do something that we'd never done before-curationthrough the delicate and rigorous application of our shared knowledge. For an extended moment, we agreed, as a group of individuals to an 'interdependence' that took place around the worktable in the living room of my apartment. Since we were not originating new work together, we were never dependent on one another. Our decision making process evolved and responded to the constraints and possibilities of fixed parameters (the works of art we chose to include, our consideration of the audience I viewer's experience and the particularities of the space, (Siobhan Davies Studios) that housed the festival. We gathered around the table because we wanted to and because we shared a temporary aim. So the quality of our listening and our speaking was undiluted by the kinds of obligations and responsibilities that a more long-term, institutionalised work place might have demanded. We were amateurs-but only in the sense of loving what we were doing.

These few examples hint at the many artistic collaborations which I've been lucky enough to experience and which have shaped and re-shaped the imaginary edges of myself as profoundly as the more somatic ways I've lived in my body (dancing, training, travelling, filming) have left their mark on my physicality. Their constituent parts drift between words, silences, shared activities and incomplete gestures.

I've shared intuitive split-second exchanges with others that have unfolded in my mind over months and years. (In fact one such exchange on a dance film shoot led me to marry my now husband!) And I've had long and meaningful dialogues over years which when they have quietly ended due to inevitable shifts in circumstance, interest or economics, have rapidly faded in my thoughts-leaving a palpable but unnamable residue. Having formed a life through these dialogues or collaborations, I know they can be as rich and intense in their emotional quality as any love affair. And they require the ability to hold, but not hold onto. 
An image of myself as a cartoon character pops into my head: an animated Lucy with layers of collaborative residue vibrating around me like the pencil lines visible in a line boil' ${ }^{\prime}$ around a hand-drawn character. The lines are only visible when I'm standing still.

Outside of the different kinds of collaborative making I have participated in, there are other kinds of dialogues or exchanges with peers, participants, students, writers-ofbooks-I'm-reading and artists-of-many-kinds-some-of-whom-I've-never-even-met which all form the landscape of my work and practice. They are the soil and the nourishment that allows me to flourish. They are also my creative barometerproviding unspoken feedback on my ability to accept, initiate, invent, respond, recognise and to be inside and outside as well as in-between. These exchanges are the foundations of what I think of when I think of my community. These dialoguers describe my dependence and my independence, I live my life in relation to these others. This is both the difficulty and the wonder. And despite technology's offer of almost limitless potential connection and despite the very real daily need for recognising our relationship to the ecologies of people and places we live in, to really experience ourselves as interdependent continues to be confrontational.

The writer and Buddhist monk, Thich Nhat Hanh coined the term 'interbeing' to describe the implicit interdependence of all elements-known and unknown-of the universe we live in. He writes:

If you are a poet, you will see clearly that there is a cloud floating in this sheet of paper. Without a cloud, there will be no rain; without rain, the trees cannot grow; and without trees, we cannot make paper. The cloud is essential for the paper to exist. If the cloud is not here, the sheet of paper cannot be here either. So we can say that the cloud and the paper inter-are. "Interbeing" is a word that is not in the dictionary yet, but if we combine the prefix "inter-" with the verb "to be," we have a new verb, inter-be. ${ }^{7}$

Responding to the invitation to write this small essay has itself subtly re-shaped my edges-it's pulled me in different directions and created the space for me to acknowledge what for me ultimately sustains any life in art-making: the funny, banal, provocative, profound, idealistic, cynical, hopeful, despairing, jubilant, contemplative, fearful, courageous attempts to exchange ideas that we believe in.

\section{Biography}

Lucy Cash (lucycash.com) is an artist and moving-image maker. She works with an expanded sense of choreography and an interest in extending choreographic thinking 
beyond dance in order to offer more haptic ways of relating to the world around us. In 2009 she received a screendance fellowship from South East Dance from which she developed a collaborative curatorial platform - straybird (straybird.org). straybird has created a series of innovative curations including two festivals at Siobhan Davies Studios in 2010 and 2012 (What If... and What Matters) and a mobile curation for Dance Umbrella - Stray Gifts (2013). In 2013 Lucy was awarded the first research residency at the Foundling Museum, and in 2014 she collaborated with Sheila Ghelani on Some Patterns of Current - a Dance in Libraries commission. She regularly mentors other artists, as well as teaching at various institutions (including Roehampton University, Tate Modern, Falmouth University and Siobhan Davies Dance).

\section{Notes}

${ }^{1}$ Matthew Goulish, 39 Microlectures, 10.

${ }^{2}$ Karen Christopher's writing was presented at a research sharing on Tuesday 24th February, 2015 at Roehampton University. www.karenchristopher.co.uk

${ }^{3}$ As well as making her own work, Veronica runs Wrap Arts Centre with Leo Preston: http://wrap.hdu.no/

${ }^{4}$ Here is a link to the film https://vimeo.com/21504871

${ }^{5}$ Gill began the "What" Festivals in 2009 www.independentdance.co.uk/film-and-video/ The website for "What If...." is currently offline. The website for the second festival curated by straybird (Lucy Cash and Becky Edmunds) can be found here: http://straybird.org/whatmatters/

${ }^{6}$ In hand-drawn animation, each frame of a character's movement is created by a separate drawing - fractionally different from the previous one. The 'boil' occurs through the slight imprecisions that occur between the outlines of these line drawings. In early animation these were considered imperfections. Now, when so little animation is actually hand-drawn some animators even add boil in to create a sense of authenticity.

7 Thich Nhat Hanh, Heart of Understanding, 45.

\section{References}

Goulish, Matthew. 39 Microlectures in Proximity of Performance. London: Routledge, 2000. 
Hanh, Thich Nhat. Heart of Understanding: Commentaries on the Prajnaparamita Heart Sutra. Parallax Press, 2010. 